\title{
THE USE OF BUCCAL PAD OF FAT VERSUS LEUKOCYTE-PLATELET RICH FIBRIN FOR CLOSURE OF OROANTRAL COMMUNICATION
}

\author{
Nermine Ramadan Mahmoud*
}

\begin{abstract}
Introduction: Oroantral communication (OAC) is a common complication following extraction of maxillary posterior teeth because of the close anatomic proximity of the roots to the maxillary sinus.
\end{abstract}

Aim of study: Evaluation of Buccal Pad of Fat versus Leukocyte Platelet Rich Fibrin (L-PRF) in the management of oroantral communication.

Materials and Methods: This study was carried out on 12 patients with oroantral communication. They were divided into 2 groups, 6 patients in each. In Group I, the patients were treated with buccal fat pad technique. While in group II, the patients were managed with L-PRF technique for OAC closure.

Patients were followed up for 1,3,5,7 days post-operative then weekly for 4 weeks.

Results: There was significant difference between the two groups regarding pain, and swelling however, no significant difference between both groups regarding infection during different follow up periods. No recurrence for the oroantral communication was observed in all patients of both groups after 4 weeks postoperatively.

Conclusion: The goal of closing an oroantral communications is separation of the oral cavity from the maxillary sinus and to prevent infection of the maxillary sinus.

KEYWORDS: Buccal fat pad flap, L-PRF, Oro-antral communication.

\section{INTRODUCTION}

Oroantral communication (OAC) is an iatrogenic complication following extraction of the maxillary posterior teeth (premolars and molars) ${ }^{[1-4]}$. Due to the close relationship of the roots to the antrum and partially very thin maxillary sinus floor. ${ }^{[1,2-5]}$.
Although, it may be developed as a result of prevalence of the inflammatory odontogenic pathologic processes through the maxillary alveolar process to the Schneiderian sinus membrane. Periodontal infections and other factors are the least prevalent. Further complications of OAC may result from the removal of cysts or tumors,

\footnotetext{
* Lecturer oral and maxillofacial surgery; Oral Surgery Department ; October 6 University
} 
implant placement, maxillofacial surgery (Le Fort osteotomies), and pathological procedures like osteomyelitis. ${ }^{[5]}$

OAC are variable in sizes accordingly treatment choice was selected, communications that are 1 to $2 \mathrm{~mm}$ in diameter have the potential to heal spontaneously due to formation of a blood clot and secondary healing if no infection is present ${ }^{[1-}$ ${ }^{3,6,7]}$. However, OAC greater than $3 \mathrm{~mm}$ in diameter may not heal spontaneously which develop into an oroantral fistula $(\mathrm{OAF})^{[2,3,8-11]}$. With larger sized OACs greater than $3 \mathrm{~mm}$ in diameter surgical closure is indicated, numerous techniques have been developed ${ }^{[12-15]}$.

Soft tissue coverage considered as the most important factor in healing of OAC. Primary closure directly over OAC have resulted in a relatively large number of failures due to insufficient soft tissue coverage ${ }^{[7-9]}$. Therefore, mucosal closure using a buccal mucoperiosteal flap or a palatal rotational flap should be considered, especially for larger OACs [9- 11]. Buccal pad of fat was used also as another treatment option for closure of OACs that was first described in 1802 by $\boldsymbol{B I C H A T}{ }^{[12]}$, thereafter many studies were done to prove success of buccal pad of fat in closure of OACs ${ }^{[13-14]}$.

Buccal fat pad flap (BFP) has been used for reconstruction of maxillary defects induced by tumors since it was first reported by EGYEDI in $1977^{[15]}$. From then, many clinical applications of BFP have been introduced. The buccal fat pad appears 3 months in utero and continuously grows until birth ${ }^{[16]}$. There is little change in volume of buccal fat during aging. Therefore, it is a reliable flap for the reconstruction of oral due to BFP's rich vascularity, low donor-site morbidity, simple surgical procedure for grafting and its proximity to recipient site. It is composed of lobes and highly mobile structures which has a main body and four extensions: temporal, buccal, pterygoid, and pterygopalatine $^{[17]}$.
It protrudes at anterior border of masseter muscle and extends to parotid duct, where it rests on the buccopharyngeal fascia, which covers buccinator muscle ${ }^{[18]}$. The main body is surrounded by the buccinator muscle, masseter muscle, and zygomatic arch, positioned along posterior maxilla and covered with a thin capsule. The parotid duct pierces buccinator at anterior border of buccal fat $\operatorname{pad}^{[18]}$ [Figure 1]. The average volume of the fat pad is $9.6 \mathrm{~mL}$ (range, $8.3-11.9 \mathrm{~mL}$ ). The average weight of the fat pad is $9.3 \mathrm{~g}$ (range, 8-11.5 $\mathrm{g}$ ). When properly dissected, the buccal fat pad provides a $6 \times$ $5 \times 3$-cm graft. The average thickness is $6 \mathrm{~mm}$, and this can cover an area of $10 \mathrm{~cm}^{2[18,19]}$.

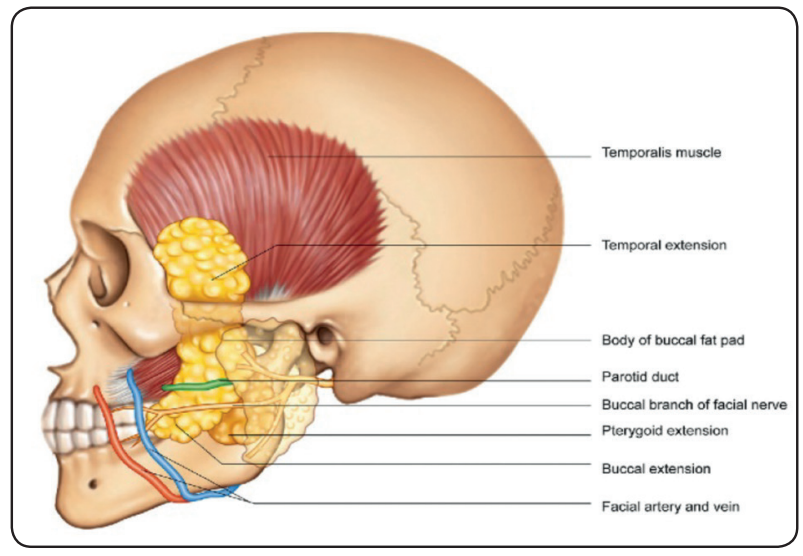

Fig. (1) Diagram showing buccal pad of fat body and extensions and their blood supplies

Regenerative medicine has emerged as a novel strategy utilizing bioactive modifiers such as plateletrich plasma (PRP) and leucocyte platelet-rich fibrin (L-PRF) in management of oral and maxillofacial soft and hard tissue wounds ${ }^{[20,21]}$. Leucocyte platelet rich fibrin (L-PRF) is a second-generation autologous platelet concentrate that introduced by Choukroun et al ${ }^{[22]}$ who announced that L-PRF contains 7 times more growth factors than PRP and are released at a slower rate throughout the wound healing process ${ }^{[22-24]}$. It is prepared without the use of any exogenous components such as bovine thrombin and anticoagulant required in preparation of platelet-rich plasma (PRP) ${ }^{[21]}$. 
Within the platelets are fibrin, fibronectin and vitronectin that are secreted and act as adhesion molecules for cell migration. Growth factors that enhance the production of fibroblasts, osteoblasts, the extracellular matrix, stem cell differentiation and the inflammatory response are the following: platelet derived growth factor bb (PDGF-bb), insulin-like growth factor-1 (IGF-1), transforming growth factor-b1 (TGF-b1), fibroblast growth factor (FGF), vascular endothelial growth factor (VEGF), epidermal growth factor (EGF) and bone morphogenetic protein (BMP). Leukocyte cytokines discovered in matrix include interleukins- (IL-1b, 4 and 6) and tumor necrosis factor-alpha (TNF-a). All growth factors and stem cells contained within the L-PRF matrix have been shown to stimulate hard and soft tissue wound healing [20-26].

\section{AIM OF STUDY:}

Evaluation of Buccal Pad of Fat versus Leukocyte Platelet Rich Fibrin (L-PRF) in the management of oroantral communication.

\section{PATIENTS AND METHODS}

Twelve patients (7 females and 5 males) with oroantral communications were selected from the Oral and Maxillofacial Surgery department, Faculty of Dentistry, October 6 University with an age range between 24 and 40 years. Patients suffering from any systemic diseases were excluded from the study.

The patients were divided into two groups, six patients in each group. In the first group (I), closure of OAC was performed utilizing Buccal pad of fat technique while in the second group (II), the oroantral closure was managed utilizing L-PRF technique. Both techniques were performed under local anaesthesia 4\% Articaine hydrochloride with epinephrine 1:100,000.

\section{Clinical examination and Diagnosis}

Diagnosis represents the first decision-making about the patient. It determines all subsequent treatments and the course of each patient. It mainly based on a comprehensive evaluation of dental and medical examination and patient history, specifically looking for diagnostic criteria for maxillary sinusitis.

\section{Procedure}

Valsalva test: The patient is instructed to try to exhale through a blocked nasal airway. However, a negative test does not exclude the possibility of antral perforation. It is worth noting that the detection of small perforations is not always possible ${ }^{[27]}$.

\section{Cheek-blowing test:}

The patient is asked to blow air into the cheeks against a closed mouth. This test is considered a risk of antral complications due to the spread of microorganisms from the oral cavity into the maxillary sinus.

\section{Exploration of the perforation with probing:} Attempt of probing the fistula is likely to result in sinusitis or widening of the fistula due to pushing of foreign. (Figure 2a)

Radiographic investigation of OAC site was required to validate the clinical findings and investigate the presence of foreign body within the antrum although the discontinuity of maxillary sinus floor. (figure $2 b$ )

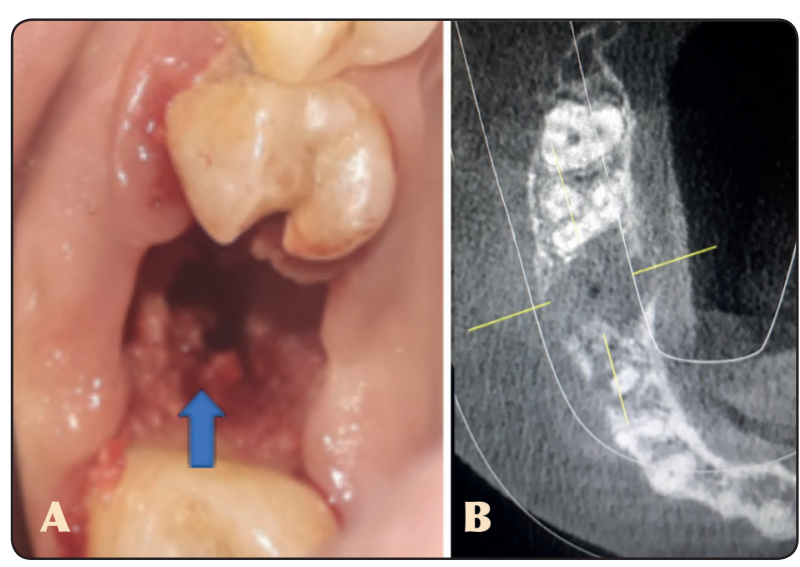

Fig. (2) a: clinical photograph showing the OAC related to extracted maxillary first molar. b: CBCT axial view showing OAC related to the extraction site. 


\section{Perioperative Management}

Preoperatively, the affected maxillary sinus should be irrigated through the fistulous opening with normal saline followed by an iodine-containing solution diluted with normal saline (1:1 betadine) to eradicate infection. This regimen should be administered until the lavage fluid is clear and no longer contains inflammatory exudates.

\section{Buccal Pad of Fat Technique}

The BFP was exposed by a 2-cm horizontal periosteal incision, lateral to the maxillary buttress, extending backward above the maxillary second molar tooth. Blunt dissection through the buccinators and loose surrounding fascia allowed

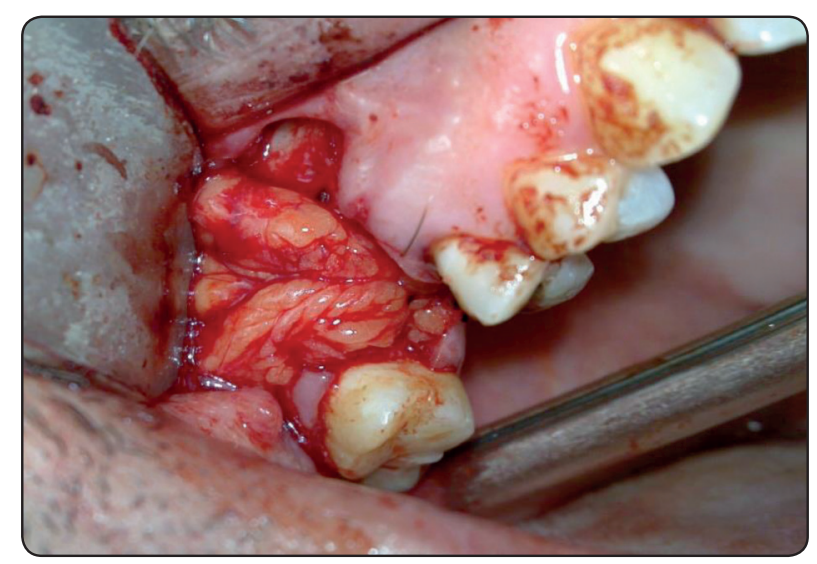

Fig. (3) Clinical photograph showing BFP advanced into bony defect in case No 1 Group I the BFP to herniate into the mouth. The body of the BFP and the buccal extension were gently mobilized by blunt dissection, taking care not to disrupt the delicate capsule and vascular plexus and to preserve as wide a base as possible. Pressure on the cheek helped to express the fat into the mouth. After the pad had been dissected free from the surrounding tissues, it was grasped with vascular forceps, gently pulled out and was gently advanced into bony defect and secured underneath the palatal mucosa without tension with 4-0 vicryl sutures (Figure 3-4 a,b). Mucoperiosteal flap was replaced in its original position, and sutures were inserted between BFP and buccal flap so that part of BFP was exposed in the oral cavity and finally a stabilizing suture was placed between buccal flap and palatal mucosa.

\section{L-PRF preparation technique}

Blood samples (9 millilitres of fresh venous blood) were collected from the patient's cubital fossa, using tubes (Becton Dickinson Vacutainer) without anticoagulant. Tubes were shacked well to prevent blood coagulation, then were putted into blood centrifuge.

The blood samples are then centrifuged at $3,700 \mathrm{rpm}$ for 12 minutes, fibrin clot containing the platelets was located in middle of tube just between the red blood cell layer at bottom and

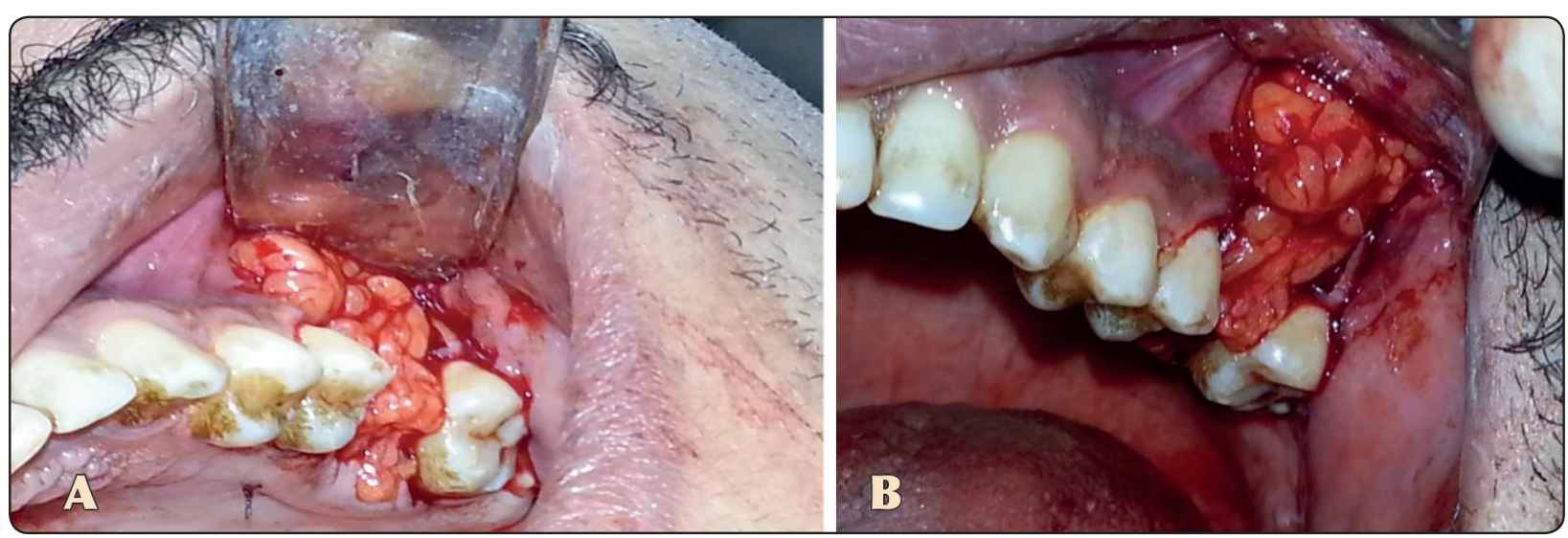

Fig. (4) a,b: clinical photograph showing BFP advanced into bony defect and secured underneath the palatal mucosa in case No 2 Group I 


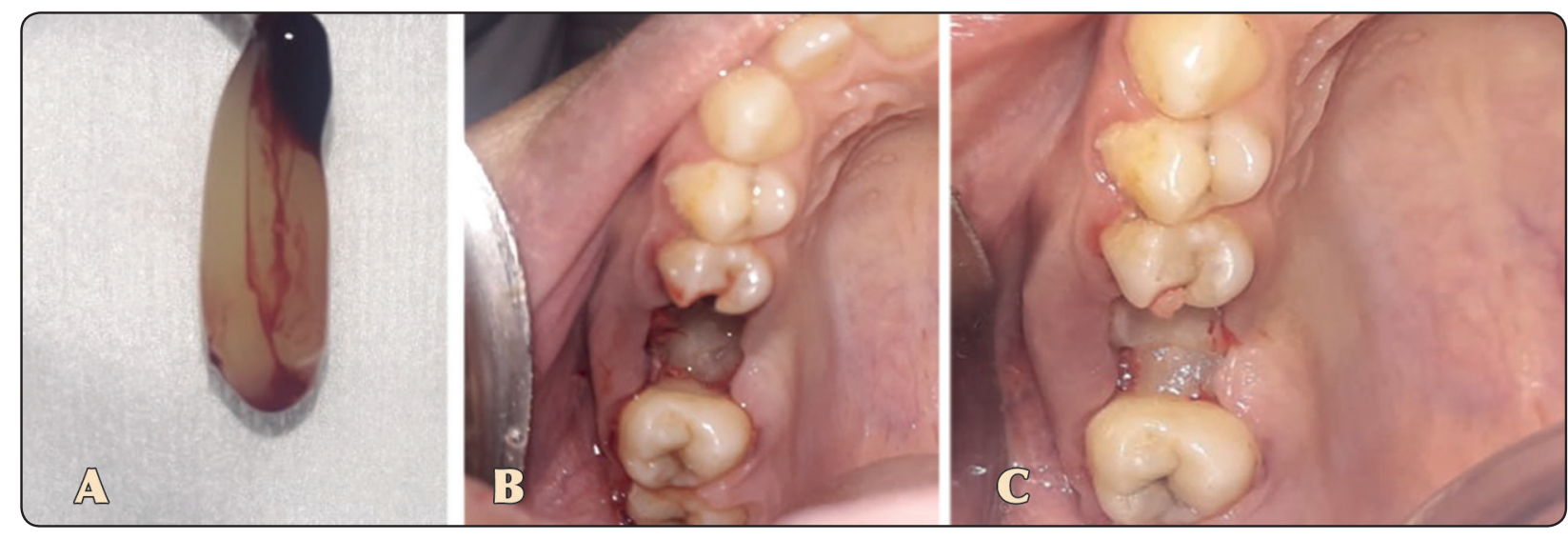

Fig. (5) A: Clinical photograph of L-PRF matrix excised from the platelet poor fraction of the PRF clot and ready to be placed into the point of care. B: clinical photograph showing one of the L-PRF matrix clots was placed directly into the OAC extraction site. C: clinical photograph showing the second L-PRF matrix clot is placed directly over the extraction site

acellular plasma at the top. This clot was removed carefully from the tube and the attached red blood cells were scrapped off and discarded. About 4.5 to $5 \mathrm{ml}$ of L-PRF is obtained per $9 \mathrm{ml}$ tube as shown in (figure 5a).

To repair the OAC, the extraction site is debrided and prepared to receive one of the L-PRF matrix clots was placed directly into the OAC extraction site. (Figure 5b) The second L-PRF matrix clot is placed directly over the extraction site (Figure 5c). The buccal and palatal ends of the L-PRF matrix clot are adapted to the maxilla for passive, tensionfree closure using resorbable sutures (figure 6).

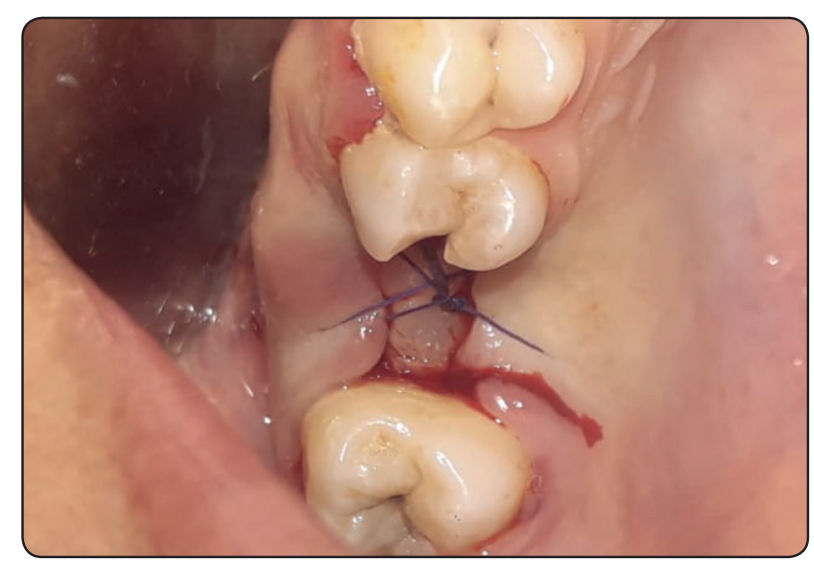

Fig. (6) Clinical photograph showing the buccal and palatal ends of the L-PRF matrix clot are adapted to the maxilla for passive, tension-free closure using resorbable sutures.

\section{Postoperative Management}

The patients were instructed not to eat hard food items. They should eat soft food items and drink fluid from the opposite side to avoid trauma to operated site. Strenuous physical activities which can increase the intra-sinusoidal pressure should be avoided until healing occurs.

Patients were instructed to avoid activities that may produce pressure changes between the nasal passages and oral cavity for at least two weeks, such as nose blowing and sneezing with a closed mouth that was prohibited for 2 weeks. Patient should open mouth while coughing or sneezing and should not roll tongue over suture line or the flap for 07 days after surgery. The wound should be kept clean with warm saline intrabuccal mouth rinses with $0.12 \%$ chlorhexidine Di-gluconate solution for two weeks. Use of straw or smoking is prohibited. All patients were received amoxicillin plus clavulanic acid (Augmentin), $1 \mathrm{~g}$ twice daily, or clindamycin, $300 \mathrm{mg} 3$ times daily for at least 5 days, and a decongestant nasal drop (Otrivin 0.05\%). Nasal decongestants shrink the nasal mucosa and keep the antral opening patent for drainage. Non-steroidal anti-inflammatory drugs (NSAIDS) were prescribed for pain control Ibuprofen $600 \mathrm{mg} 3$ times/day. 
Seven days after surgery the OAC was repaired as granulation tissue was observed in the extraction site. At 4 weeks post-closure of the OAC, what was consistently observed is complete closure of the $\mathrm{OAC}$ due to regeneration of the gingival soft tissues.

The criteria for successful repair was complete healing of the flap without symptoms or signs of leakage.

\section{RESULTS}

All of the 12 selected patients were enrolled completely in the study. Their age ranged from 24 to 40 years with mean age 33.17 years. All patients tolerated the procedure well under local anaesthesia.

The two selected surgical techniques for OAC closure were:

In the first group (I), closure of OAC was performed utilizing Buccal pad of fat technique while in the second group (II), the oroantral closure was managed utilizing L-PRF technique.

\section{Postoperative follow-up}

All patients were recalled immediately postoperative after one day (D1), three days (D3), seven days (D7), two weeks (W2), three weeks (W3) and four weeks (W4). Pain assessment was done at D1, D3, D7, W2, W3 and W4. Swelling assessment was done at D1, D3 and D7. Infection, wound dehiscence and recurrence were assessed at D7, W2, W3 and W4.

\section{* VAS:}

Pain intensity was assessed using a 10-point visual analogue scale (VAS), with the patient placing a mark on the scale to indicate an intensity range from no pain ' 0 ' to severe/unbearable pain '10'. [28] The severity of the pain was evaluated on D1, D3, D7, W2, W3 and W4.

\section{* Facial swelling:}

The degree of facial swelling was determined by a modification ${ }^{[29]}$ of the tape measure method described by Gabka and Matsumara ${ }^{[30]}$.
Three measurements were made between five reference points:

a) The distance between the lateral corner of the eye and angle of the mandible,

b) The distance between the tragus and soft tissue pogonion, and

c) The distance between the tragus and outer corner of the mouth.

The mean of these three measurements was calculated. Measurements were taken pre-operatively and on postoperative days 1,3 and 7 .

No recurrence for the oroantral communication was observed in all patients of both groups after 4 weeks postoperatively.

\section{Demographic data:}

1- Age: The age of patients in the BPF group ranged from 24 to 40 years with mean age 33.17 and standard deviation (SD) 6.4, which is closely to the L-PRF group as the age ranged from 21 to 42 years with mean age 32.67 and SD 7.6.

2- Gender: The whole study included 7 female (58.3\%) and 5 male $(41.7 \%)$ patients. The BPF group included 3 female, 3 male patients, and the L-PRF group included 4 female and 2 male patients. (Figure 7)

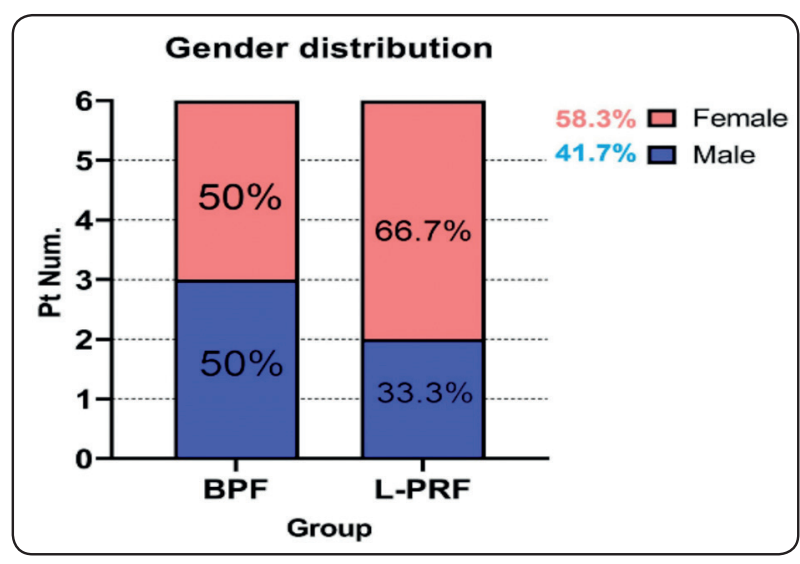

Fig. (7): bar chart representing mean $\%$ of gender distribution in both groups. 
3- Related site of OAC: All cases in this study were related to extraction of 1 st molar ( 8 cases) which represent $66.67 \%$ of total cases and 2 nd molar (4 cases) which represent $33.3 \%$ of total cases in the maxilla. (Figure 8 )

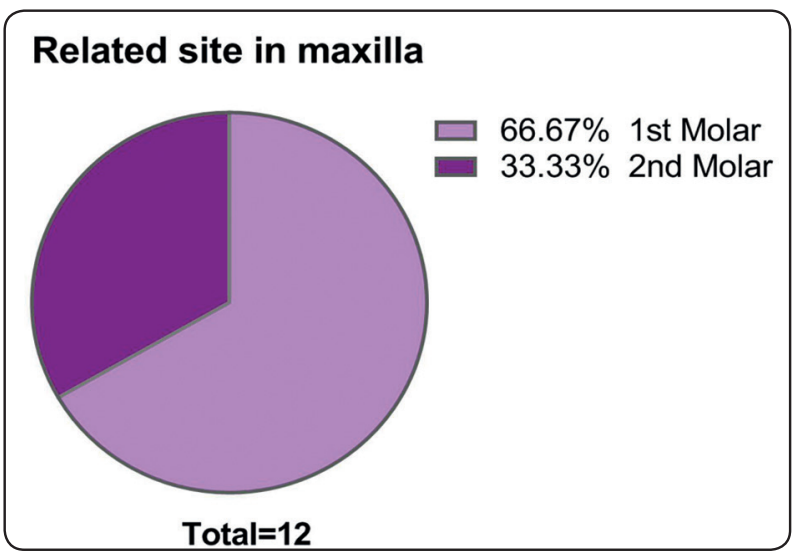

Fig. (8): Showing mean $\%$ of the related site of OAC

\section{Clinical assessment:}

All patients' assessment data was tabulated and analysed using GraphPad Prism version 8.3 (GraphPad Software, San Diego California USA). Two-way ANOVA test was used to compare between the two groups at the time intervals.

1- Pain: The pain scores for each patient in both groups was recorded immediate postoperatively and 1, 3 and 7 days as well as second, third and fourth week postoperatively and the mean scores for both groups were calculated. (Figure 9)

The mean of pain score for the BPF group was 1.3, while for the L-PRF group was 0.45 with standard error 0.20 . The difference between the two means was statistically significant with $P$ value-0.0196.

2- Swelling: Swelling assessment was relied on stable landmarks, that were; (A)Lateral canthus, (B)Soft tissue Gonion, (C)Mid of tragus, (D) Commissure of mouth and (E)Soft tissue Pogonion. The distances between A-B, C-D and $\mathrm{C}-\mathrm{E}$ were recorded for each patient then collected together at the pre-operative stage and at the time intervals D1, D3 and D7. Two way ANOVA test was used to compare swelling

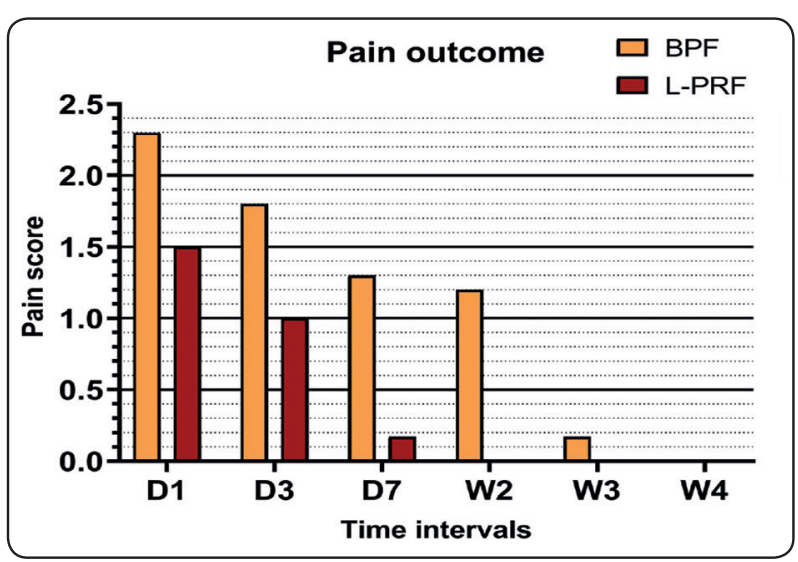

Figure (9): bar chart representing the mean pain outcome in both groups at all follow up intervals

scores between the two groups at the time intervals. (Table 1) (Figure 10)

The mean of swelling score for the BPF group was 33.33 pre-operative and 34.59 at the time intervals, while for the L-PRF group was 33.53 pre-operative and 33.72 at the time intervals. The difference between the two means at the time intervals postoperative was statistically non-significant with P value - 0.2875 .

The difference between both groups was found to be highly statistically significant at the immediate post-operative period. After 1 and 3 days, swelling was present in all patients in group I and 3 patients in group II. After 7 days, swelling was present in 3 patients in group I. No swelling was present in group II. After 10 days postoperatively, swelling was present in only 2 patients in group I. At the end of the follow up period, none of the patients in both groups were presented with swelling.

TABLE (1): Showing the mean of swelling scores at the pre-operative stage and at the time intervals for both groups

\begin{tabular}{|c|c|c|}
\hline & BPF group & L-PRF group \\
\hline Pre-operative & 33.33 & 33.53 \\
\hline D1 & 34.58 & 33.92 \\
\hline D3 & 35.72 & 33.72 \\
\hline D7 & 33.47 & 33.53 \\
\hline
\end{tabular}




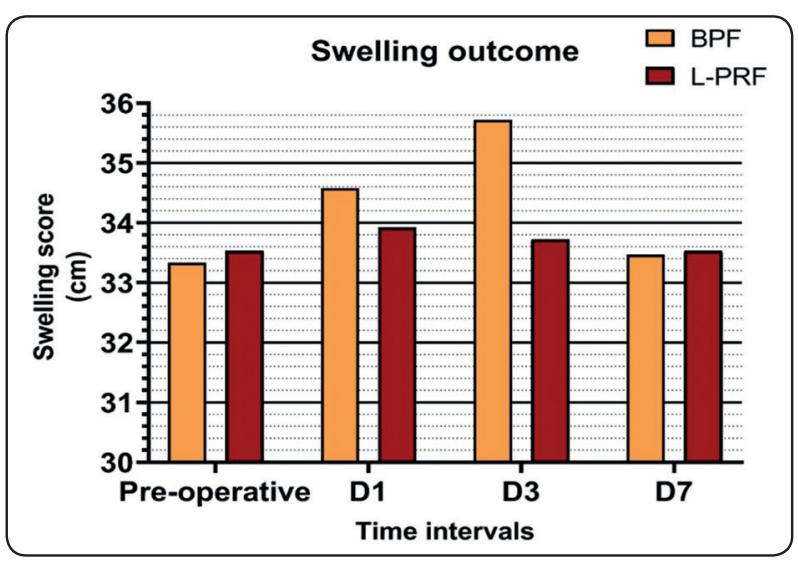

Fig. (10): Bar chart of the swelling outcome for both groups

3- Infection or wound dehiscence: All patients in the present study were free from any signs of infection or wound dehiscence throughout all time intervals (D7, W2, W3 and W4). No statistically difference was found between both groups at all follow up interval.

4- Recurrence: There are no clinical signs of recurrence of OAC throughout the follow up period of the study on all patients without exception. No statistically difference was found between both groups at all follow up interval.

\section{DISCUSSION}

Acute oroantral communications that size range from 1 to $2 \mathrm{~mm}$ in diameter, heal spontaneously where sinus free from any infection. However, oroantral defects that are greater than $5 \mathrm{~mm}$ and present for longer than 3 weeks will epithelialize into chronic oroantral fistulas requiring secondary surgical closure. ${ }^{[9]}$

In the present study, the size of oroantral communication in both groups were greater than 4 $\mathrm{mm}$ in diameter which correlates with the finding of Punwutikorn et al..$^{[3]}$ reporting that OAC having a diameter of $2 \mathrm{~mm}$ and less has a great possibility of spontaneous healing while bigger defects usually require surgical intervention due to increased risk of inflammation of the maxillary sinus associated with large bony defects.
Many techniques have been described for OAC closure, including local and soft tissue flaps. Other techniques include grafts such as autografts, xenografts, allografts, alloplastic materials, and other methods like guided tissue regeneration (GTR) or immediate implantation of a dental implant. Local buccal soft tissue flaps are often indicated for closure of small to moderate size defects ${ }^{[31]}$.

Borgonovo et al. ${ }^{[32]}$ proposed the use of the buccal flap for the closure of oroantral fistulae of moderate size, provided that not too posteriorly located; the palatal flap is best used in the case of fistulae located in the premolar teeth area; and the buccal flap combined with displacement of the buccal fat pad (BFP) is appropriate for fistulae located in the third molar area.

Ideally, a combination of buccal advancement flap technique with buccal pad of fat can be used to cover BFP as an additional tissue in cases of deficient fats for closure. ${ }^{[33]}$ Furthermore, singlestage alveolar augmentation with autogenous bone graft and platelet-rich fibrin (PRF) has found its application as a non-invasive contemporary technique for closure of OAC ${ }^{[34,35]}$.

The results of our study were in agreement with those of Dolanmaz et al, ${ }^{[36]}$ have considered the pedicled BFP flap to be an acceptable and reliable alternative in management of acute or chronic oroantral communication, and it seems to be the best choice of treatment, especially in recurrent oroantral fistulae. In their series of 75 cases, all of them had a favourable healing course after the operation, and the wounds became successfully epithelized in 3-4 weeks after surgery. The buccal pad of fat has rich in blood supplies including maxillary artery and both superficial and deep temporal artery ${ }^{[18]}$. There are a lot of capillary networks within the capsules that cover the fat pad. Arterioles enter the capsule from several directions and break up into capillary plexuses. Most drains into the facial vein. Stensen's duct is an adjacent anatomic structure, so it is easily encountered when extracting the buccal fat pad ${ }^{[18]}$. 
The success rate in BFP group was $100 \%$ in Abuabara A et al, study ${ }^{[9]}$, they concluded that buccal fat pad seemed to be the best choices for treatment when a larger communication existed (>5 mm). Other authors also recommend the reconstruction of defects measuring under $5 \times 4 \mathrm{~cm}$ without tension when using pedicled buccal fat pad

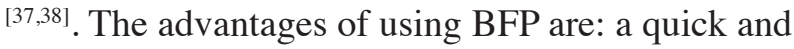
simple procedure, minimum failures rates, local anesthesia, no visible scars, low morbidity and no loss of sulcus depth ${ }^{[13,39]}$

On our study we didn't used an acrylic splint post-operative, based on that done by Logan et al, [40] who announce that acrylic surgical splint can be used successfully when a surgical intervention is contraindicated because of immunosuppression. According to Hanazawa et al ${ }^{[41]}$, when fat tissue is exposed to the oral environment, it becomes epithelialized and it is gradually replaced by fibrous conjunctive tissue within a 30-40-day postoperative, without any functional damage to treated site.

L-PRFhas been shown to stimulate wound healing at the site of tissue injury by the recruitment of cells, such as osteoblasts, endothelial cells, chondrocytes and fibroblasts ${ }^{[26,42-44]}$. These specialized cells are involved in angiogenesis and wound healing. As the fibrin matrix is slow to dissolve, it has been demonstrated that by the seventh day of wound healing, L-PRF releases the largest amount of PDGF-AB that is involved in angiogenesis and neocollagenesis. By day 14, enormous quantities of TGF beta 1 are expressed ${ }^{[23]}$. Transforming growth factor beta-1 has been shown to facilitate the growth of epithelial cells and endothelial cells. L-PRF also contain substantial amounts of VEGF that enhances epithelial healing, tissue vascularization and soft tissue regeneration ${ }^{[22,45]}$.

In accordance to another studies ${ }^{[13,39]}$, Our findings demonstrated that facial swelling and trismus are considered disadvantage of BFP, that was overcomes by the use of the other technique L-PRF which was easiest than the BFP.
Our study was in agreement to another done in 2019 by Cameron ${ }^{[46]}$ who announced additional advantages of this technique that the centrifuge is inexpensive and requires minimal training for the clinician and their support staff. The procedure can be completed under local anaesthesia, or conscious sedation in the office. For the patient, there is minimal postoperative pain and bleeding compared to other surgical procedures used to close an OAC.

L-PRF was less traumatic compared to BPF in closure of $\mathrm{OAC}$ with minimal postoperative recovery for the patient, on the other hand, Buccal Pad of Fat was considered as a good blood nourishment supply to the defect area.

\section{CONCLUSION}

The goal of closing an oroantral communications is separation of the oral cavity from the maxillary sinus and to prevent infection of the maxillary sinus. Regenerative medicine that uses the patient's own autologous growth factors in the L-PRF matrix is a novel alternative strategy that should be considered when the surgeon is confronted with having to close an OAC instead of harvesting a soft tissue rotational flap from the cheek or palate of the maxilla. Although, it was friendly for the clinician confronted with the complication of OAC of the posterior maxilla. It does not require advanced surgical skill and experience with harvesting and rotating soft tissue flaps in the oral cavity as with other techniques.

\section{REFERENCES}

1. Wowern N. Frequency of oro-antral fistulae after perforation to the maxillary sinus. European Journal of Oral Sciences. 1970; 78:394-6.

2. Ehrl PA: Oroantral communication. Epicritical study of 175 patients, with special concern to secondary operative closure. Int J Oral Surg. 1980; 9:351-358.

3. Punwutikorn J, Waikakul A, Pairuchvej V. Clinically significant oroantral communications a study of incidence and site. International Journal of Oral and Maxillofacial Surgery. 1994; 23:19-21. 
4. Killey HC, Kay LW. An analysis of 250 cases of oroantral fistula treated by the buccal flap operation. Oral Surgery, Oral Medicine, Oral Pathology. 1967; 24:726-39.

5. Rothamel D, Wahl G, d'Hoedt B, Nentwig G-H, Schwarz F, Becker J. Incidence and predictive factors for perforation of the maxillary antrum in operations to remove upper wisdom teeth: Prospective multicentre study. British Journal of Oral and Maxillofacial Surgery. 2007; 45:387-91.

6. Awang MN. Closure of oroantral fistula. International Journal of Oral and Maxillofacial Surgery. 1988; 17:110-5.

7. Visscher SH, van Minnen B, Bos RRM. Closure of oroantral communications: a review of the literature. Journal of Oral and Maxillofacial Surgery. 2010; 68:1384- 91.

8. Poeschl PW, Baumann A, Russmueller G, Poeschl E, Klug C, Ewers R. Closure of oroantral communications with bichat's buccal Fat Pad. Journal of Oral and Maxillofacial Surgery. 2009; 67:1460-6.

9. Abuabara A, Cortez ALV, Passeri LA, de Moraes M, Moreira RWF. Evaluation of different treatments for oroantral/oronasal communications: experience of 112 cases. International Journal of Oral and Maxillofacial Surgery. 2006; 35:155-8.

10. Haanaes HR, Pedersen KN. Treatment of oroantral communication. International Journal of Oral Surgery. 1974; 3:124-32.

11. Lee J-J, Kok S-H, Chang H-H, Yang P-J, Hahn L-J, Kuo Y-S. Repair of oroantral communications in the third molar region by random palatal flap. International Journal of Oral and Maxillofacial Surgery. 2002; 31:677-80.

12. BICHAT FMX. Use of buccal fat pad to repair intraoral defects: review of 30 cases. Br J Oral Maxillofac Surg 1997: 35: 81-84.

13. Rapidis AD, Alexandridis CA, Eleftheriadis E, Angelopoulos AP. The use of the buccal fat pad for reconstruction of oral defects: Review of the literature and report of 15 cases. J Oral Maxillofac Surg. 2000; 58:158-163.

14. Killey HC, Kay LW. Observations based on the surgical closure of 362 oro-antral fistulas. Int Surg. 1972; 57:545-549.

15. Egyedi P. Utilization of the buccal fat pad for closure of oroantral and/or oro-nasal communications. Journal of Maxillofacial Surgery. 1977; 5:241-4.

16. Arce K (2007) Buccal fat pad in maxillary reconstruction. Atlas Oral Maxillofac Surg Clin North Am 15(1):23-32
17. Singh J, Prasad K, Lalitha RM, Ranganath K (2010) Buccal pad of fat and its applications in oral and maxillofacial surgery: a review of published literature (February) 2004 to (July) 2009. Oral Surg Oral Med Oral Pathol Oral Radiol Endod 110(6):698-705

18. Tostevin PM, Ellis H (1995) The buccal pad of fat: a review. Clin Anat 8(6): 403-406

19. Stuzln JM, Wagstrom L, Kawamoto HK, Baker TJ, Wolfe SA (1990) The anatomy and clinical applications of the buccal fat pad. Plast Reconstr Surg 85(1):29-37

20. Marx RE. Platelet-rich plasma: evidence to support its use. Journal of Oral and Maxillofacial Surgery. 2004; 62:489-96.

21. Dohan DM, Choukroun J, Diss A, Dohan SL, Dohan AJJ, Mouhyi J, et al. Platelet-rich fibrin (PRF): A second generation platelet concentrate. Part I: Technological concepts and evolution. Oral Surgery, Oral Medicine, Oral Pathology, Oral Radiology, and Endodontology. 2006; 101:e37-44.

22. Dohan DM, Choukroun J, Diss A, Dohan SL, Dohan AJJ, Mouhyi J, et al. Platelet-rich fibrin (PRF): A second generation platelet concentrate. Part II: Plateletrelated biologic features. Oral Surgery, Oral Medicine, Oral Pathology, Oral Radiology, and Endodontology. 2006; 101:e45-50.

23. He L, Lin Y, Hu X, et al. A comparative study of plateletrich fibrin (PRF) and platelet-rich plasma (PRP) on the effect of proliferation and differentiation of rat osteoblasts in vitro. Oral Surg Oral Med Oral Pathol Oral Radiol Endod. 2009; 108:707-713.

24. Kobayashi E, Flückiger L, Fujioka-Kobayashi M, Sawada $\mathrm{K}$, Sculean A, Schaller B, et al. Comparative release of growth factors from PRP, PRF, and advanced-PRF. Clinical Oral Investigations. 2016; 20:2353-60.

25. Anitua E, Tejero R, Zalduendo MM, Orive G. Plasma rich in growth factors promotes bone tissue regeneration by stimulating proliferation, migration, and autocrine secretion in primary human osteoblasts. Journal of Periodontology. 2013; 84:1180-90.

26. Roy S, Driggs J, Elgharably H, Biswas S, Findley M, Khanna $S$, et al. Platelet-rich fibrin matrix improves wound angiogenesis via inducing endothelial cell proliferation: PRFM in wound angiogenesis. Wound Repair and Regeneration 2011 ; 19:753-66.

27. Kretzschmar DP, Kretzschmar JL. Rhinosinusitis: review from a dental perspective. Oral Surg Oral Med Oral Pathol Oral Radiol Endod. 2003; 96(2):128-35. 
28. WI, Campbell, S. Lewis. Visual analogue measurement of pain, Ulster Med J, 59, 1990,149e54.

29. S. Schultze-Mosgau, R. Schmelzeisen, Fro“ - JC. lich, H. Schmele, Use of ibuprofen and methylprednisolone for the prevention of pain and swelling after removal of impacted third molars, J Oral Maxillofac Surg, 53,1995,2-7.

30. J. Gabka, T. Matsumara. Measuring techniques and clinical testing of an anti-inflammatory agent (tantum), Munch Med Wochenschr,113, 1971,198-203.

31. Awang MN. Closure of oroantral fistula. Int J Oral Maxillofac Surg. 1988; 17(2):110-5.

32. Borgonovo AE, Berardinelli FV, Favale M, Maiorana C. Surgical options in oroantral fistula treatment. Open Dent J. 2012;6:94-8.

33. Batra H, Jindal G, Kaur S. Evaluation of different treatment modalities for closure of oro-antral communications and formulation of a rational approach. J Maxillofac Oral Surg. 2010;9(1):13-8.

34. Kapustecki M, Niedzielska I, Borgiel-Marek H, Rozanowski B. Alternative method to treat oroantral communication and fistula with autogenous bone graft and platelet rich fibrin. Med Oral Patol Oral Cir Bucal. 2016; 21(5):e608-13.

35. Ghanaati S, Herrera-Vizcaino C, Al-Maawi S, Lorenz J, Miron RJ, Nelson K, Fifteen years of platelet rich fibrin in dentistry and oromaxillofacial surgery: how high is the level of scientific evidence? J Oral Implantol. 2018; 44(6):471-92.

36. D. Dolanmaz, H. Tuz, S. Bayraktar, M. Metin, E. Erdem, T. Baykul, Use of pedicled buccal fat pad in the closure of oroantral communication: analysis of 75 cases, Quintessence international, 35(3), 2004, 241-6.

37. J. Singh, K. Prasad, RM. Lalitha, K. Ranganath, Buccal pad of fat and its applications in oral and maxillofacial surgery: a review of published literature (February) 2004 to (July)
2009, Oral Surg Oral Med Oral Pathol Oral Radiol Endod,110, 2010, 698-705.

38. ES. Kim, Clinical evaluation of the effectiveness of pedicled buccal fat pad grafts in closure of oroantral communications, J Korean Assoc Oral Maxillofac Surg, 26, 2000, 297-300.

39. FL. Pereira, GJ. Farah, LG. Passeri, AJ. Pavan. Aplicação do Corpo Adiposo Bucal para o Encerramento de fistula Bucosinusal. Relato de Caso, Rev Port Estomatol Cir Maxillofac,45, 2004,221-6.

40. Logan RM, Coates EA. Non-surgical management of an oro-antral fistula in a patient with HIV infection. Aust Dent J. 2003;48(4):255-8.

41. Y. Hanazawa, K. Itoh, T. Mabashi, K. Sato, Closure of oroantral communications using a pedicled buccal fat pad graft, J Oral Maxillofac Surg, 53,1995,771-5.

42. Chen F-M, Wu L-A, Zhang M, Zhang R, Sun H-H. Homing of endogenous stem/progenitor cells for in situ tissue regeneration: Promises, strategies, and translational perspectives. Biomaterials. 2011; 32:3189-209.

43. Kumar YR, Mohanty S, Verma M, et al. Platelet rich fibrin: The benefits. Br J Oral Maxillofac Surg. 54:57, 2016.

44. Schliephake H. Clinical efficacy of growth factors to enhance tissue repair in oral and maxillofacial reconstruction: a systematic review: clinical efficacy of growth factors. Clinical Implant Dentistry and Related Research. 2015; 17:247-73.

45. Gülşen U, Şentürk MF, Mehdiyev İ. Flap-free treatment of an oroantral communication with platelet-rich fibrin. British Journal of Oral and Maxillofacial Surgery. 2016; 54:702-3.

46. Cameron Y. S. Lee. Closure of an Oroantral Communication Using Leucocyte-Platelet Rich Fibrin: A Novel Technique Using Regenerative Medicine J Den Max Surg, 2(1): 101-106 (2019) 